\title{
Commentary: Brain injury in congenital heart disease-Who knows what happened first?
}

\author{
Lok Sinha, MD, Nobuyuki Ishibashi, MD, and Can Yerebakan, MD
}

\footnotetext{
From the Department of Cardiovascular Surgery, Children's National Heart Institute, The George Washington University School of Medicine and Health Sciences, Washington, DC.

Disclosures: Authors have nothing to disclose with regard to commercial support.

Received for publication Sept 5, 2019; revisions received Sept 5, 2019; accepted for publication Sept 5, 2019.

Address for reprints: Can Yerebakan, MD, Department of Cardiovascular Surgery, Children's National Hospital,

The George Washington University School of Medicine and Health Sciences, 111 Michigan Ave NW, Washington, DC 20010 (E-mail: cyerebakan@ childrensnational.org).

J Thorac Cardiovasc Surg 2020;159:278-9

$0022-5223 / \$ 36.00$

Copyright (c) 2019 Published by Elsevier Inc. on behalf of The American Association for Thoracic Surgery https://doi.org/10.1016/j.jtcvs.2019.09.002
}

Excellent outcomes in the surgical treatment of congenital heart disease have already moved our focus to the suboptimal long-term neurodevelopmental outcomes in our patients. The understanding of central nervous system alterations after hypoxemic insult has recently elucidated the microscopic level of the damage, with microglia emerging as one of the potential key targets. ${ }^{1,2}$ Microglial cells are known with their role in synapse formation and blood-brain barrier development in the fetal brain and their contribution to establishing network connectivity during postnatal brain development. ${ }^{2-4}$ The focus on different morphologic types of microglia and their role in embryonic vasculogenesis, neurogenesis, and building neuronal network during brain development gives another glimpse of hope in bridging the knowledge gap between normoxic and hypoxic fetal brain development, particularly in the understanding of the long-term neurodevelopmental outcome in survivors with congenital heart disease. $^{3-6}$

In this issue of the Journal, Lawrence and colleagues ${ }^{7}$ from Children's Hospital of Philadelphia report that prenatal hypoxemia alters microglial morphology in experiments that used an assembly, an "artificial womb." The experiments were conducted in 8 fetal sheep equally divided into 2 groups, hypoxic and normoxic. Hypoxic animals were subjected to low blood oxygen levels for $22 \pm 2$ days. Lawrence and colleagues ${ }^{7}$ concluded that the morphologic alterations in microglia were associated with an increase in a number of round or amoeboid (loss of ramified cytoplasmic processes) subtype of microglial cells in hypoxic animals relative to normoxic and control animals. Further, they noted that there were no inflammatory lesions, apoptosis rate was similar in all groups, and no gliosis or necrosis was seen in this relatively shortterm hypoxemic period. They are to be congratulated for their first-time demonstration of structural alteration of microglia during hypoxia that impaired morphology and ital heart disease.

\section{References} Med. 2017;23:1018-27.

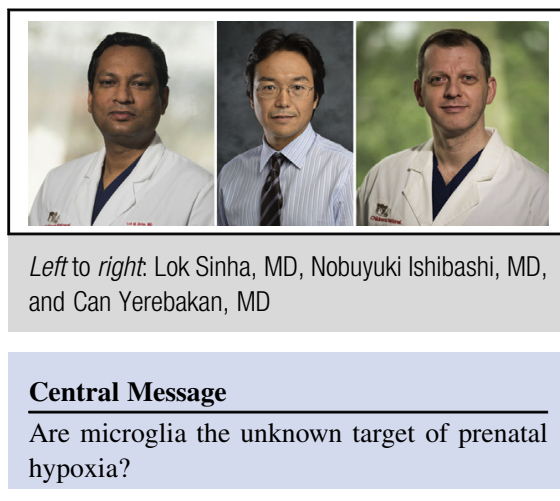

See Article page 270.

possibly function, which in turn could contribute to the pathogenesis of myelin formation and eventually alteration in neurodevelopmental outcome in later life. The design of the "artificial womb," also called the Extrauterine Environment for Neonatal Development (EXTEND), that assist regulated fetal growth should be equally appreciated. ${ }^{8}$

Despite obvious limitations in this innovative model of artificially regulated prenatal hypoxia, as discussed in detail by Lawrence and colleagues, ${ }^{7}$ this study and the previous data from the same group present exceedingly important steps toward the understanding of a potential "heart-brain axis," which implies structural brain changes at microscopic level in neonates with congenital heart disease, maybe just beyond the impact of hypoxemia. The future may allow us to study the prenatal brain once successful simulation of different congenital cardiac anomalies in animal models becomes feasible. The aim remains to target potential risks for a healthy neuronal development early and possibly at various stages of the patient's course by being aware of the timing of the damage. Ultimately, innovative and effective strategies for neurologic protection may be implemented according to the expected damage in the preoperative, intraoperative, and postoperative periods in congenital heart surgery.

We congratulate Lawrence and colleagues ${ }^{7}$ for their contributions in their effort to find causal factors for wellproven neurodevelopmental delay in patients with congen-

1. Salter MW, Stevens B. Microglia emerge as central players in brain disease. Nat 
2. Miyamoto A, Wake H, Ishikawa AW, Eto K, Shibata K, Murakoshi H, et al. Microglia contact induces synapse formation in developing somatosensory cortex. Nat Commun. 2016;7:12540.

3. Mallard C, Tremblay M, Vexler Z. Microglia and neonatal brain injury. Neuroscience. 2019;405:68-76.

4. Hagemeyer N, Hanft KM, Akriditou MA, Unger N, Park ES, Stanley ER, et al. Microglia contribute to normal myelinogenesis and to oligodendrocyte progenitor maintenance during adulthood. Acta Neuropathol. 2017;134: 441-58.

5. Licht DJ, Shera DM, Clancy RR, Wernovsky G, Montenegro LM, Nicolson SC, et al. Brain maturation is delayed in infants with complex congenital heart defects. J Thorac Cardiovasc Surg. 2009;137:529-36; discussion 536-7.

6. Kinney HC, Panigrahy A, Newburger JW, Jonas RA, Sleeper LA. Hypoxicischemic brain injury in infants with congenital heart disease dying after cardiac surgery. Acta Neuropathol. 2005;110:563-78.

7. Lawrence KM, McGovern PE, Mejaddam A, Rossidis AC, Baumgarten $\mathrm{H}$, Kim AG, et al. Prenatal hypoxemia alters microglial morphology in fetal sheep. J Thorac Cardiovasc Surg. 2020;159:270-7.

8. Lawrence KM, McGovern PE, Mejaddam A, Rossidis AC, Baumgarten H, Kim A, et al. Chronic intrauterine hypoxia alters neurodevelopment in fetal sheep. $J$ Thorac Cardiovasc Surg. 2019;157:1982-91. 